\title{
Detection of Colony Adhesion Factors and Genetic Background of Adhesion Genes Among Multidrug- Resistant Uropathogenic Escherichia coli Isolated in Iraq
}

\author{
Munim Radwan Ali ${ }^{1}$ and Anfal Mohammed Khudhair ${ }^{2}$ \\ ${ }^{1}$ Al-Musatnsirihyah University, College of Science, Department of Biology, Baghdad, Iraq. \\ ${ }^{2} \mathrm{Al}-$ Iraqia University, College of Medicine, Baghdad, Iraq.
}

\begin{abstract}
Escherichia coli remain significant problem caused urinary tract infection; Results indicated a higher urinary tract infection in women compared with men across all age groups. Phylogenetic analysis showed that majority of uropathogenic isolated $E$. coli belong to phylogroup B2 followed by $D$. The isolates showed the existence of the first type of fimbriae, maximum $P$ fimbriae positive isolates 74/94 (80.43\%) were widely correlating with common UTI. colony adhesion factor (CAFĐ) represented in $40(43.47 \%)$ and $5(5.43 \%)$ colony adhesion factor (CAF $\varnothing$ ). Six major clusters (A-F) were identified depending on antibiograms typing. $B 2$ is the most phylogenetic type showed wide range of resistant from 1 to 12 resistant to antibiotic of remaining strains. 14 isolates (15.21\%) were detected as ESâLs producers and 30 isolates $(32.60 \%)$ of them were AmpC $\beta$-lactamases producers. prevalence of virulent genes occurred in 51 papC (55.43\%), 66 fim $H$ (71.73\%) and SfaDE detected in low occurrence 21(22.82). These results emphasize the low or moderate resistant to antibiotics focused in isolates with high genetic content.These results indicated that the greater the resistance to antibiotics the less the genetic expression of the virulence factors, this confirms the reverse relationship. The genes required for uropathogenicity in a single isolate may not reflect virulence in another isolate. Pathogenicity is a multi-factor characteristic, the result of adhesion-related genes which interact in separate set in various genetic backgrounds.
\end{abstract}

Keywords: UTI ,E. coli , Phylogenetic analysis, adhesion factor, virulent genes.

\footnotetext{
*Correspondence: mnumbio77@yahoo.com
}

(Received: 03 October 2018; accepted: 20 November 2018)

Citation: Munim Radwan Ali and Anfal Mohammed Khudhair, Detection of Colony Adhesion Factors and Genetic Background of Adhesion Genes Among Multidrug-Resistant Uropathogenic Escherichia coli Isolated in Iraq, J Pure Appl Microbiol., 2018; 12(4): 2017-2025. http://dx.doi.org/10.22207/JPAM.12.4.38

(c) The Author(s) 2018. Open Access. This article is distributed under the terms of the Creative Commons Attribution 4.0 International License which permits unrestricted use, sharing, distribution, and reproduction in any medium, provided you give appropriate credit to the original author(s) and the source, provide a link to the Creative Commons license, and indicate if changes were made. 


\section{INTRODUCTION}

Urinary tract infections (UTIS) are common bacterial infections associated with much morbidity and health care $\operatorname{cost}^{1}$. Escherichia coli strains capable of causing disease outside the gastrointestinal tract belong to a diverse group of isolates referred to as uropathogenic E. coli (UPEC) ${ }^{2}$. UPEC mediated several virulence factors, which help bacteria to colonize the urinary tract and begin infections ${ }^{3}$. Fimbriae are categorized serologically by their hemagglutination pattern and receptor specificities as mannose sensitive (MSHA) or mannose resistance hemagglutination (MRHA) ${ }^{4}$. Despite the vast subclass of adhesins that have been reported in UPEC, Type I (MSHA) and $P$ (MRHA) are the widespread fimbriae in UPEC strains. They play a remarkable role in binding and invasion of the bladder and kidney ${ }^{5}$. In $E$. coli pathogenicity associated island (PAI) many virulence gene were expressed. The important ones are the 'adhesions, which help to break the inertia of urinary bladder mucus and help to attach to them ${ }^{6}$. Type I pili, are mediated and expressed by a fim gene cluster in the most of UPEC strains ${ }^{7}$. pap genes coded $\mathrm{P}$ pili (pyelonephritis-associated pili, PAP), which have essential role in upper UTIs ${ }^{8}$ and S fimbrial adhesion $(s f a)^{9}$. UTI multi-drug resistant $E$. coli has gradually increased. essentialy as a result of the incidence of fluoroquinoloneresistant and ESBL-producing isolates ${ }^{10}$. The decreased expression in virulence mediated genes and invasive capacity associated with MDR strains ${ }^{11}$. Many predispose disease are associated with many factors lead to genetic background ${ }^{12}$. There is real proof that the connection among virulence ability of $E$. coli, phylogenetic background, and resistance to antibiotics are incident, resulting from their diverse mutual ${ }^{13}$.

The distribution pattern of adhesion virulence factor encoding fim $H, S f a D E$ and pap $C$ genes in the multidrug resistance UPEC isolates are as yet indistinct in different parts of Iraq. So, this study is aimed to determine the coordination between the genetic backgrounds, coexist, correlation of phenotypic and genotypic adhesive virulence factors and antibiotic resistance profile among the UPEC.

\section{MATERIAL AND METHODS \\ Study Population}

Urine samples from 450 cases (both male and female of age 15-70 years) of UTI were collected during Jan 2012 to June 2012, for isolation of $E$. coli. Patients on antibiotic therapy were excluded from the study.

\section{Collection of Urine Samples}

Early morning midstream urine samples were collected using a sterile plastic container with screw cap tops with name, age, sex, time of collection ${ }^{14}$.

\section{Isolation and identification of $E$. coli}

All urine samples were cultured and incubated overnight at $37^{\circ} \mathrm{C}$ on blood agar and MacConckey agar; further incubation for 24 hours were done if the remained negative. A positive specimen yields colonies $\left(\geq 10^{5} \mathrm{cfu} / \mathrm{ml}\right)$ and the microscopic detection of bacteriuria when PMNs $\left(\geq 8\right.$ leukocytes $/ \mathrm{mm}^{3}$ ). No mixed infections were encountered ${ }^{15}$. further identification of isolates were done by specific biochemical tests, and API 20E test system (Bio- Merieux) considered confirmatory test ${ }^{16}$.

\section{Antibacterial Agents Susceptibility}

Antibacterial susceptibility of E. coli was tested on Mueller-Hinton agar by the disk diffusion method according to ${ }^{17}$. The antibiotic discs used in this study were Amoxicillin/clavulanic acid (30mg; 20:10), Amoxicillin (30 $\mu$ g), Cefoxitin $(30 \mu \mathrm{g})$, Cefotaxime $(30 \mu \mathrm{g})$, Cefotazidime, $(30 \mu \mathrm{g})$, ciprofloxacin $(5 \mu \mathrm{g})$, Cefepime $(30 \mu \mathrm{g})$, Imipenem $(10 \mu \mathrm{g})$, Levofloxacin $(5 \mu \mathrm{g})$, Kanamycin $(30 \mu \mathrm{g})$.

\section{ESBL and AmpC screening}

Production of ESBL was detected by double disc synergy test according to CLSI guidelines ${ }^{17}$. For $A m p C$ screening done according to ${ }^{18}$.

\section{Detection of colony adhesion factors (CAF)}

Three types of colony adhesion factors $\mathrm{I}, \mathrm{II}$ and III were detected according to ${ }^{19}$.

Bacterial adherence to epithelial cells, screening The adherence ability of the E. coli isolates to uroepithelial cells was assayed as described by ${ }^{20}$.

\section{Preparation of bacterial DNA}

Template DNA was prepared by boiling method that described by ${ }^{21}$. 


\section{Phylogenetic groups procedure}

Phylogenetic groups were defined as described by ${ }^{22}$.

\section{PCR amplification of virulence factor genes procedure:}

Detection of papC (type P pili) gene was performed by PCR. The primer sequences were reported by ${ }^{23}$ and obtained from an Alpha DNA company (USA). The program, for papC gene the reactions condition included an initial denaturation at $94^{\circ} \mathrm{C}$ for $1 \mathrm{~min}$ consisted of 30 cycles of $94^{\circ} \mathrm{C}$ for one min, specific annealing temperature $63^{\circ} \mathrm{C}$ for 30 seconds, and a final extension at $72^{\circ} \mathrm{C}$ for 90 seconds. For fim $\mathrm{H}$ and $S f a D E$, the primers sequences were previously reported by(24).The initial denaturation of reactions mixtures at $94^{\circ} \mathrm{C}$ for $5 \mathrm{~min}$ followed with 30 cycles of $94^{\circ} \mathrm{C}$ for one min, specific annealing temperature $58^{\circ} \mathrm{C}($ fim $\mathrm{H})$ and $63^{\circ} \mathrm{C}(S f a D E)$ for one min and $68^{\circ} \mathrm{C}$ for three min, and a final extension at $72^{\circ} \mathrm{C}$ for 7 min. The detection of PCR products was performed on 1.5 $\%$ agarose gels by electrophoresis and visualized under UV light.

\section{RESULTS}

A total number of 450 Urine samples, from which 148 (32.88\%) were found to contain heavy and appreciable bacterial growth (significant bacteriuria) while 302 (67.11\%) had no appreciable bacterial growth. Their ages ranging from 15 to 70 years, 392 females and 58 males. The majority of Escherichia coli in UTI cases, 67 cases, were predisposed by adult women married. 25 cases of girls unmarried and 11 cases of children 15 year for both sex. The laboratory criterion for acute E. coli UTI was the presence of a positive culture response with at least $10^{5} \mathrm{CFU}$ of $E$. coli per $\mathrm{ml}$ of clean-voided urine. Table 1.
Analysis of Phylogenetic group's demonstrated that $E$. coli isolates presented into four phylogenetic groups: groups A, B1, B2, and D. The distribution of phylogroup B2 (57 isolates) was at high percentage as compared with phylogroup $D$ (16 isolates), while B1and A groups distributed as $(10,9$ isolates) respectively.

In the present study, $80.43 \%$ of the UTI isolates revelation the existence of type 1 fimbriae (MSHA). While only $43.47 \%$ of UTI E.coli isolates have P fimbriae (MRHA). Simple UTI and cystitis showed highly expression of type 1 fimbriae. detection of colony adhesion factor (CAFĐ) represented in 40 (43.47\%) uropathogenic E. coli, while only 5 (5.43\%)isolates were positive for colony adhesion factor (CAFIII).

Adherence of $E$. coli isolates to uroepithelial cells were showed in all isolates $100 \%$. Although, all isolates considered uropathogenic according to number of bacteria/cells, Table 2 .

The dendrogram of the antibiogram profiles created by UPGMA showed the presence of high similarity in banding patterns of isolates among every group which was about $23 \%$ - $95 \%$. All 92 local isolates under study design and distributed to Six major clusters (A-F) were identified with a

Table 1. Data of Escherichia coli UTI patients

\begin{tabular}{ll}
\hline Data & Variable \\
\hline 15-70 years & Age of patients \\
Gender of patients & $\begin{array}{l}\text { 392:58 Female : male } \\
\text { Adult pregnant } \\
\text { women uTI }\end{array}$ \\
& Adult women UTI \\
92 cases & Girls UTI \\
81 cases & Men UTI \\
58 cases & Children UTI \\
\hline
\end{tabular}

Table 2. The adhesion factor and Percentage of colony adhesion factors pattern of E. coli clinical isolates:

\begin{tabular}{|c|c|c|c|c|}
\hline \multicolumn{3}{|c|}{ Adhesion factor } & \multirow[b]{2}{*}{$\begin{array}{l}\text { Adherence to } \\
\text { uroepithelial cells }\end{array}$} & \multirow[t]{2}{*}{ Isolates } \\
\hline CAFIII & CAFII & CAFI & & \\
\hline 5 & 40 & 74 & 92 & Number of adhesion \\
\hline 5.43 & 43.47 & 80.43 & 100 & Percentage \% ( N 92) \\
\hline
\end{tabular}


small dissimilarity between clusters depending on the type of multidrug resistance, in order to facilitate the distribution process. Table 3.

Phylogenetic groups A, B1, B2, and D, which showed different patteren in susceptibility to antibiotics. Multidrug resistance showed in all isolates. B2 is the most phylogenetic type showed wide range of resistant from 1 to 12 resistant to antibiotic of remaining strains.

In the present study, Out of 92 of $E$. coli, 14 isolates (15.21\%) were detected as ES $\beta$ Ls producers and 30 isolates (32.60\%) of them were AmpC $\beta$-lactamases producers by phenotypic method ESBL positive isolates were more resistant to all tested antibiotics except for imipenem compared to the non-ESBL isolates.

The local uropathogenic $E$. coli isolates distributed to three clusters depending on the type of Quinolones and Fluroquinolones resistance. The highest rate of multidrug resistance was observed with GroupC 26 (31.52\%) isolates, in which this isolate was able to resist all Quinolones and Fluroquinolones antimicrobial agents.as well as Group B distinguished in 11(11.96\%) isolates. While the lowest Quinolones and Fluroquinolones resistance was notice with Group A 55(59.78\%) isolates in which sensitive for all these antimicrobial agents.

Table 3. Distribution of $E$. coli phylogenetic group according to antibiogram profiles dendrogram analysis

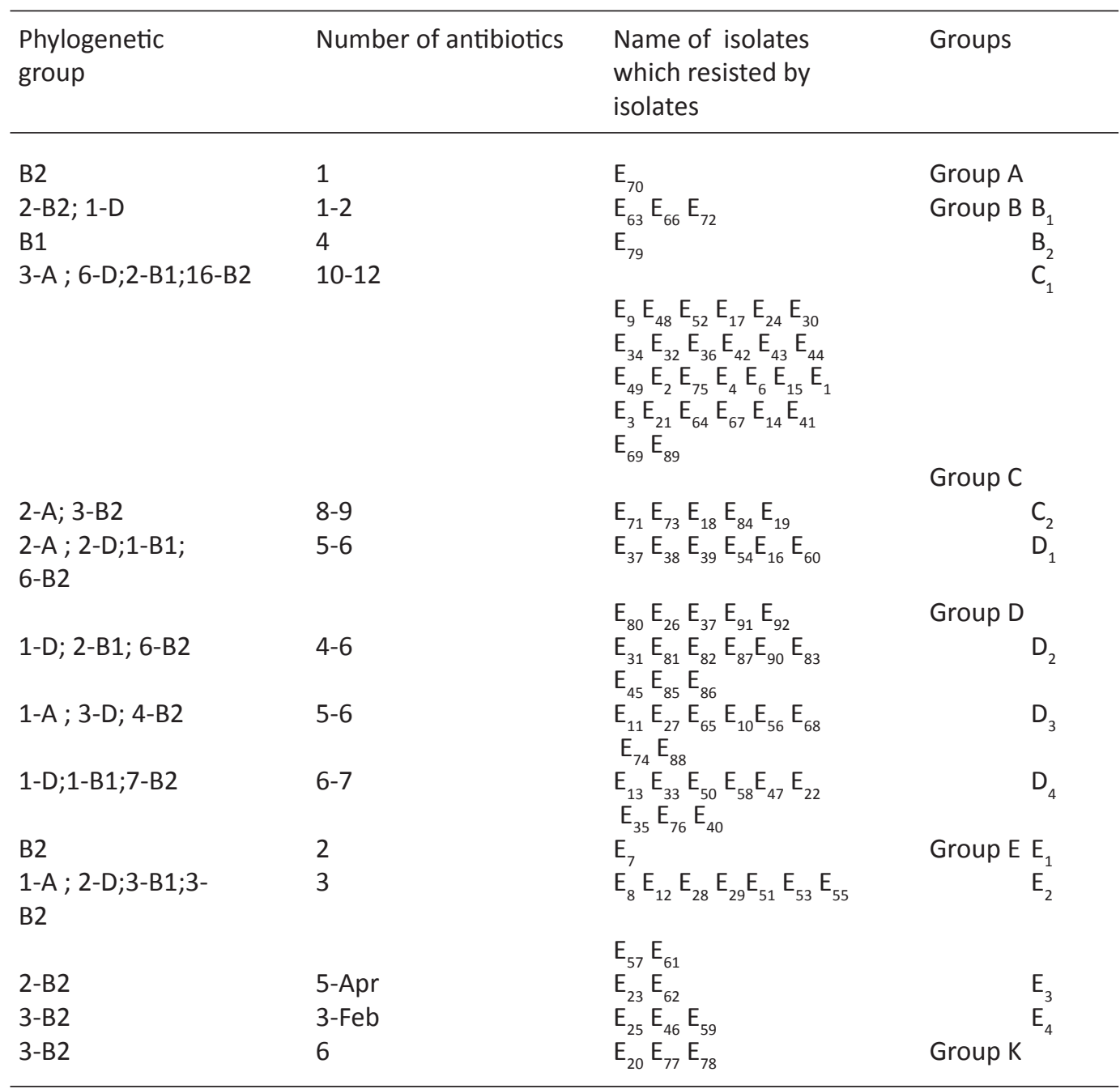


Isolates with multidrug resistance antibiotics was found it to be related with colony adhesion factor, $16(17.39 \%)$ isolates have first colony adhesion factor (CAFI) resisted 5-6 antibiotics represented high rate of isolates harboring $\mathrm{CAFI}$, while resistant to 12 antibiotics appear only in 3 isolates .Percentage \%1.08 of isolates which resisted 12 antibiotics and have only one isolate have second colony adhesion factor (CAFII), while there was a clear rule in the production of moderate resistance 5-6 antibiotics pattern in 13 isolates with high percentage value $14.13 \%$ between CAFII isolates. In the same manner isolates have third colony adhesion factor (CAFIII), resist 5-6 antibiotics were predominant in percentage $22.8 \%$. Table 4 .

Collection of 92 uropathogenic E. coli isolates were screen for selectable adhesion virulence factor encoding fim $H, S f a D E$ and pap $C$ genes. Results showed that the prevalence of

Table 4. The percentage of correlation between colony adhesion factors and multidrug resistance pattern of all $E$. coli isolates

\begin{tabular}{lllllllllll}
\hline & N R & 12 & 11 & 10 & 9 & 9 & 7 & $5-6$ & $4-3$ & $2-1$ \\
CAFI & NMDR & 3 & 15 & 8 & 5 & 12 & 6 & 16 & 7 & 2 \\
& $\%$ & 3.26 & 16.3 & 8.69 & 5.43 & 13.04 & 6.52 & 17.39 & 7.6 & 2.17 \\
CAFI & N R & 12 & 11 & 10 & 9 & 9 & 7 & $5-6$ & $4-3$ & $2-1$ \\
& NMDR & 1 & 5 & 1 & 3 & 9 & 1 & 13 & 6 & 1 \\
& $\%$ & 1.08 & 5.43 & 1.08 & 3.26 & 9.78 & 1.08 & 14.13 & 6.52 & 1.08 \\
CAFII & N R & 12 & 11 & 10 & 9 & 9 & 7 & $5-6$ & $4-3$ & $2-1$ \\
& NMDR & 2 & 8 & 5 & 2 & 10 & 6 & 21 & 7 & 4 \\
& $\%$ & 2.17 & 8.69 & 5.43 & 2.17 & 10.86 & 6.52 & 22.82 & 7.6 & 4.34 \\
\hline
\end{tabular}

N R Number of antibiotics which resisted by isolates

NMDR Numbers of the multidrug resistance isolates and continue CAF

$\%$

Percentage of \% N92 CAF

virulent genes occurred in 51 papC (55.43\%), 66 fim $H(71.73 \%)$ and SfaDE it can detected in low occurrence 21(22.82) isolate of E.coli, FimH gene was the common occurrence virulence factor detected. Fiften isolate gave negative results for all adhesive virulence genes. Distributed based on the appearance of genes in in each isolate, all studied uropathogenic $E$. coli possess 8 patterns of virulence gene, indicate to as EG (Table 5).The pattern EG6 characterized by fim $\mathrm{H}$ was one of the most common patterns that had only one gene spread and was observed in 23 isolates. Among the isolates that owned fim $\mathrm{H}$ and papC gene, from where $39.39 \%$ of isolates that was fim positive, represented by 26 isolates and which was predominate pattern (EG2).

\section{DISCUSSION}

The study indicates that a higher ratio of UTI in females 392 than in males 58 . In this regard ${ }^{25}$ noted the incidence of UTI is higher in women compared with men across all age groups. It came in agreement with ${ }^{26}$ which showed the majority
Table 5. Pattern of Adhesive virulance gene in E. coli

\begin{tabular}{|c|c|c|c|c|}
\hline \multirow[b]{2}{*}{$\begin{array}{l}\text { No. of } \\
\text { isolates }\end{array}$} & \multicolumn{4}{|c|}{ Adhesive virulence gene } \\
\hline & sfaBC III & Fim H & pap C & Pattern \\
\hline 14 & + & + & + & EG1 \\
\hline 26 & - & + & + & EG2 \\
\hline 4 & + & - & + & EG3 \\
\hline 7 & - & - & + & EG4 \\
\hline 3 & + & + & - & EG5 \\
\hline 23 & - & + & - & EG6 \\
\hline 0 & + & - & - & EG7 \\
\hline \multirow[t]{2}{*}{15} & - & - & - & EG8 \\
\hline & 21 & 66 & 51 & Total \\
\hline
\end{tabular}

of Escherichia coli in UTI cases in 92 females than in males 47 cases only.

The result of current study on the line with study by ${ }^{27}$ that showed high parentage of UTI of pregnant woman, is due to physiological changes. While didn't agree with study in Iraq by ${ }^{28}$ that reported was only $3.44 \%$ of pregnant woman 
infected UTI for age between 21-25 years. More than $85 \%$ of UTIs caused by E. coli, according to ${ }^{29}$. Prevalence of phylogenetic group B2 followed by $D$ among others, represented that the virulence isolates most of time indicated UTI. Many studies state that $E$. coli strains causing UTI mostly belong to phylogroups B2 and D rather than $\mathrm{B} 1$ and $\mathrm{D}^{30}$.

From the study result, the absence of fimbriae or other surface adhesion systems effect on bacterial adhesion. Irreversible attachment happened by Fimbriae to the uroepithelial cell membrane. While recently reported, 74 isolates $(80.43 \%)$ were able to express type 1 fimbriae and another strains expressed type $P$ but not type 1 fimbriae. Current study relatively agree with 26 that show (89\%) of $E$. coli expression of $\mathrm{P}$ fimbriae. While it decreased to $17(63 \%)$ UTI isolates of $E$. coli expression of $\mathrm{P}$ fimbriae in Iraqi study by ${ }^{32}$.

In the study observation, most $P$ fimbriae positive isolates were so associated with simple UTI. in the same manner ${ }^{33}$ showed there is no relation between the incident or symptoms severity and the site of infection and expression of fimbria in $E$. coli isolates from urine.

However (34) studies reported type 3 fimbriae expression mediated by conjugative plasmid in E. coli in .The results identified colony adhesion factor (CAFIII) rare in uropathogenic $E$. coli agree with the showed low rate of CAFIII in uropathogenic $E$. coli $3.2 \%$.

The present study indicated the relation between site of infection (lower urinary tract infections) and expression of P fimbriae. It should be noted that many of the isolates under the study have become intrusive in the possession of adhesion factors and this may indicate that adhesion is a necessary and essential step to start the infection, especially in urinary tract infections ${ }^{35}$. Reported the number of bacteria adherent to uroepithelial cells used to differentiate between uropathogenic and fecal strains.

Dendrogram indicates division isolates depending on the number of antibiotics which resisted. Only 1 isolate were placed in clusters $A$. Cluster D contained the majority of the isolates. In this cluster some isolates were a located in groups of higher or lower similarity and most strains were discriminated. The isolate no. 70 showed low percentage of similarity in the dendrogram which was only $23 \%$. This low percentage of similarity, probably as a result of the variation of the isolates source (patient's gender and age group). The cluster A contains only one isolate distinguished by being sensitive to all antibiotic and only resist to Gentamycin , in the other hand showed possession positive band in virulence gene detection only for fim $\mathrm{H}$, while showed positive result in phenotype detection for adherence to uropathogenic cells and for CAFI and CAFII. The cluster B at a linkage distance of 54 units can be grouped into 2 sub clusters $B_{1}$ and $B_{2}$. All 4 isolates in these groups are isolated from pregnant women and distinguish by sensitivity to all Fluroquinolones drugs, whereas variable in the virulence recipes. The cluster $\mathrm{C}$ consisted of only 26 isolates which differed from other cluster by having high resistance to 10-12 antibiotics. The cluster D which is the bigger one from other cluster can be grouped into 5 sub clusters. All the isolates in this cluster have moderate multi drug resistance. The cluster $\mathrm{E}$ consisted of only 16 isolates which having low resistance to 2-5 antibiotics. The cluster $\mathrm{F}$ consisted of three isolates

The results of the study showed that there is a correlation between the nature of resistance to antibiotics and the ability of bacteria to produce the virulence factors in uropathogenic E. coli. Actually, when study assessment the antibiograms of $E$. coli strains having virulence factor.

The antibiotic resistance rates generally increased over time and the last set of isolates collected were more resistant to antibiotics, as noted in a group of $\beta$-lactam antibiotics such as Amoxicillin and a group of Quinolones antibiotics such as Ciprofloxacin the isolates collected were more resistant reach to $100 \%$ and $38 \%$ respectively. A high concern to the limited treatment options of multidrug-resistant clinical isolates between ESBL producing $E$. coli ${ }^{36}$.

Non-detection of certain phylogenetic group that it is resistance to antibiotics in this study, but the important noticed that phylogenetic group B2 were normally distribution in all antibiotic resistance pattern, it may indicated Phytogenic and multidrug resistance types remained largely unchanged within patients in this study.

ESBL harboring $E$. coli isolates have been found to be resistant to other antibiotics, 
especially, Fluroquinolones. Resistance to ciprofloxacin has also been observed in ESBL producing $E$. coli compared to non-ESBL isolates 37. Many reason for this coexistence of resistance to $\beta$-lactam and Quinolones, one possible explanation suggested by ${ }^{38}$ is that the bacteria are able to acquire the ability to produce ESBLs can be selected by intensive Quinolones use. Moreover, the presence of Quinolones resistance on plasmids is concerning. Carrying both ESBLs enzymes and Quinolones resistance genes no such plasmid could speed the development and speared of multidrug resistance phenotype ${ }^{39}$.

Ciprofloxacin and Nalidixic acid resistance was observed among quinolones group associated with ESBL producer isolates. ESBL and quinolone resistance genes are usually carried on mobile genetic elements ${ }^{40}$.

The results indicated that when the resistance to antimicrobial agent rate is relatively low, there is an increase in productivity of adhesion factors gradually. And clearly the theory of genetic background, that there is an inverse relationship between resistance to antibiotics and the efficacy of isolates for virulence factors, which was evident in this study. Some research replied that ability of resistance may be coordinate with the virulence factors loss in E. coli isolates ${ }^{41}$. While ${ }^{42}$ who observing association between highly virulent and multiresistant $E$. coli isolates . Finally ${ }^{26}$ find a relationship between UPEC reduced virulence and multidrug resistance.

To indicate theory of genetic background and relationship between resistance to antibiotics and the efficacy of isolates for virulence factors, some selectable adhesion genes was studded to determine the correctness of the theory obtained from the results of phenotypic characteristics out of the adhesion virulence genes, fim $\mathrm{H}$ was the most spread gene and was positive in 66 (71.73\%) isolates, followed by papC gene was present in 5 isolates among total 92 isolates. this results agree with ${ }^{43}$ whom found that fim gene was the most widespread detected in $95 \%$ of the E. coli uropathogenic isolates. Next, pap gene was identified in $57 \%$ isolates . This result is not in line with the result of Firoozeh et al. (2014) in which they reported pap was the most spread gene and was identified in 25 (16.7\%) isolates. In another study conducted by ${ }^{26}$ they found that papC gene which was predominant followed by Fim $\mathrm{H}$. The other isolates exhibited distinct diversity of gene patterns. From total of 92 local isolates 14 isolates (15.21\%) own three different adhesive studied genes. afa gene were negative in isolates, indicating afa alone is infrequent between uropathogenic isolates. This result was in agreement with the study of ${ }^{44}$ which recorded that afa gene not found in there strain. The results indicated that afa sequence is may be related with horizontal gene transfer, this agreement to ${ }^{45}$ the referred to the afa gene clusters encode a fimbrial adhesions (Afas) that are expressed by uropathogenic and diarrheaassociated $E$. coli strains .But the low appearance of afa sequence gene is depending on acquired the gene by horizontal transmission ${ }^{46}$.

\section{ACKNOWLEDGMENTS}

The Authors would like to thank ALMustansiriyah University (http://uomustansiriyah. edu.iq/) Baghdad, Iraq for its support inthe present work.

\section{REFERENCES}

1. Agarwal J, Srivastava S, Singh M. Pathogenomics of uropathogenic Escherichia coli. Indian J Med Microbiol. 2012;30(2):141-9.

2. Wang X, Yan Q, Xia X, Zhang Y, Li D, Wang C, et al. Serotypes, virulence factors, and antimicrobial susceptibilities of vaginal and fecal isolates of Escherichia coli from giant pandas. Appl Environ Microbiol. 2013; 79(17):5146-50

3. Mulvey MA. Adhesion and entry of uropathogenic Escherichia coli. Cell Microbiol. 2002; 4:257-71

4. Davis N.F., Flood H.D. InTech; The pathogenesis of urinary tract infections. Clinical management of complicated urinary tract infection; 2011, pp. 101-120.

5. Ulett G.C., Mabbett A.N., Fung K.C. The role of F9 fimbriae of uropathogenic Escherichia coli in biofilm formation. Microbiology. 2007 Jul; 153(7):2321-2331.

6. Baby,S. ; Karnaker, V.K. and Geetha, R K. Adhesins of Uropathogenic Escherichia coli (UPEC). International Journal of Medical Microbiology and Tropical Diseases, January-March,2016; 2(1): 10-18.

7. Feria C, Machado J, Correia JD, Goncalves J, Gaastra W. Virulence genes and $P$ fimbriae PapA subunit diversity in canine and feline 
uropathogenic Escherichia coli. Vet Microbiol. 2001; 82(1):81-9.

8. Slavchev,G. ; Pisareva,E. and Markova,N. Virulence of uropathogenic Escherichia coli. journal of culture collection. Volume 6, 20082009, pp. 3-9.

9. Rehman, M. U. ; Zhang, H. ; Iqbal, Mehmood, K.; Huang, S.; Nabi, F. ; Luo, H.; Lan, Y. and Li , J. Antibiotic resistance, serogroups, virulence genes, and phylogenetic groups of Escherichia coli isolated from yaks with diarrhea in Qinghai Plateau, China. Gut Pathogens.2017; 9:24

10. Falagas ME, Karageorgopoulos DE. Extendedspectrum beta-lactamase producing organisms. $J$ Hosp Infect 2009; 73:345-54.

11. Vila J, Simon K, Ruiz J, Horcajada JP, Velasco $M$, Barranco $M$, et al. Are quinolone-resistant uropathogenic Escherichia coli less virulent? J Infect Dis. 2002; 186:1039-42 10.

12. Gordon MA, Invasive nontyphoidal Salmonella disease: epidemiology, pathogenesis and diagnosis. Curr Opin Infect Dis. 2011; 24: 484489.

13. Piatti, G., A. Mannini, M. Balistreri, and A. M. Schito. Virulence factors in urinary Escherichia coli strains: phylogenetic background and quinolone and fluoroquinolone resistance. J. Clin. Microb. 2008, 46480-487.

14. Maskell,R. "Diagnosis of urinary tract infection, its causes and consequences. In: Urinary tract infection", Curr. Top. Infect. Series.3M Edward Arnold. London, pp. 21-41,1982.

15. Bonadio, M.; Meini,M. ; Spitaleri,P. and Gigli,C. "Current microbiological and clinical aspects of urinary tract infections," European Urology, vol. 40, no. 4, pp. 439-445, 2001.

16. Roy MR, Anne-Marie B, Marija T, Vicki RB, Jacinta $R$, Frances O, Nicole AL, Karl AB, Christopher KF, Martha IS, Margret EH (2004).Escherichia coli and community-acquired astroenteritis, Melbourne, Australia. Emerg. Infect. Dis. 10(10): 1797-1805.

17. CLSI Performance standards for antimicrobial susceptibility testing; Twenty- Four informational supplement. 2015, M100- S25:35-3.

18. Coudron PE. Inhibitor-based methods for detection of plasmid-mediated AmpC betalactamases in Klebsiella spp., Escherichia coli, and Proteus mirabilis. J Clin Microbiol. 2005; 43:4163-7.

19. Symth, C. J. Two Mannose resistant hem agglutinins on entrotoxigenic Escherichia coli of serotype 06:K15:H16 or H-isolated from traveler's and infantile diarrhaen. J. Gene. Microbial. 1982. Vol. 128. Pp: 2081-2096.
20. Svanborg-Eden, C.; Andersson, B.; Aniansson, G., Bacterial adherence in urinaryand respiratory tract infection.KansenshogakuZasshi, 1988; 62(suppl.): 136-148.

21. Ruppe E, Hem S, Lath S, Gautier VR, Ariey F, Sarthou JL, Monchy D, Arlet G., CTX-M $\beta$-lactamases in Escherichia coli from communityacquired urinary tract infections, cambodia. Cent. Dis. Cont. Prev., 2009; 5: 741-748.

22. Clermont, O., Christenson, J. K., Denamur, E., and Gordon, D. M. The Clermont Escherichia coli phylo-typing method revisited: Improvement of specificity and detection of new phylo-groups. Environ. Microbiol. Rep. 2013; 5, 58-65.

23. Johnson, J.R. and Stell, A.L. Extended virulence genotypes of Escherichia coli strains from patients with urosepsis in relation to phylogeny and host compromise. J Infect Dis. 2000; 181, 261-272.

24. Blackburn D. Husband A. Saldaña Z. Nada R. A. Klena J. Qadri F. Girón J. A. Distribution of the Escherichia coli common pilus among diverse strains of human enterotoxigenic $E$. coli J. Clin. Microbiol. 2009; 47(6): 1781- 1784.

25. Rowe,A.T. and Juthani-Mehta,M. Urinary tract infection in older adults. Aging health. 2013; 9(5): 10.2217/ahe.13.38.

26. Abass, S.K.; Ali, M. R. and Authman, S. H. Isolation of Multi Antibiotics Resistance Escherichia coli from urinary tract infection and the Detection of $\mathrm{PapC}$ and $\mathrm{fimH}$ virulence genes by Polymerase chain reaction Technique. Diyala journal for pure sciences. 2014; 10(1):112-127.

27. Jolley JA, Wing DA. Pyelonephritis in pregnancy: an update on treatment options for optimal outcomes. Drugs. 2010; 70: 1643-1655

28. Chateen EA, Sheelan AA, Sinan BI, Sajida K. Study of urinarytract infection among pregnant women in Kirkuk. Tikrit Med. J. 2007; 13(2):3943.

29. Sanchez et al. "In Vitro Antimicrobial Resistance of Urinary Escherichia coli Isolates among U.S. Outpatients from 2000 to 2010." Antimicrobial Agents and Chemotherapy. 2012.

30. Pirko ,E.Y. ; Munim Radwan Ali,M.R. , Naji,E.N. The Relationship between Phylogenic Typing and Antimicrobial Susceptibility Patterns ForEscherichia coliisolatedfrom Utis in Many Hospitals at Baghdad City. Journal of Global Pharma Technology. 2017; 07(9):88-97.

31. Oelschlaeger TA, Dobrindt U, Hacker J. Virulence factors of uropathogens. Curr Opin Urol 2002; 12:33.

32. Salman, R.S.; Ali, M. R. and Authman, S. H. A Multiplex PCR for Detection of hlyA, papC, and 
traT genes in multidrug resistance Escherichia coli isolated from pregnant women. AJPS, 2013; 13(2):129-138.

33. Johnson JR. Virulence factors in Escherichia coli urinary tract infection. Clin Microbiol Rev; 1991; 4:80-128.

34. Ong CL, Ulett GC, Mabbett AN, Beatson $\mathrm{SA}$, Webb RI, Monaghan W, Nimmo GR, Looke DF, McEwan AG, Schembri MA: Identification of type 3 fimbriae in uropathogenic Escherichia coli reveals a role in biofilm formation. J Bacteriol. 2008; 190: 1054-1063.

35. Silveira, W.; Benetti.; F.; Lancelotti, M.;Ferreira, A.; Solferini, V. and Brocchi, M.Biological and genetic characteristics of uropathogenic Escherichia coli strains. Rev. Inst. Med. Trop. São aulo. 2001.Vol. 43. Pp: 303-310.

36. Ode T, Saito R, Kumita W, Sato K, Okugawa $S$, Moriya K, et al. Analysis of plasmidmediated multidrug resistance in Escherichia coli and Klebsiella oxytoca isolates from clinical specimens in Japan. Int J Antimicrob Agents. 2009; 34(4):347-50.

37. Pakzad I, Ghafourian S, Taherikalani M, Sadeghifard N, Abtahi H, Rahbar M, et al. qnr Prevalence in Extended Spectrum Betalactamases (ESBLS) and None-ESBLs Producing Escherichia coli Isolated from Urinary Tract Infections in Central of Iran. Iran J Basic Med Sci. 2011; 14(5): 458-64

38. Tolun, V., O. Kucukbasmaci, D. TorumkuneyAkbulut, C. Catal, M. Ang-Kucuker, and O. Ang. Relationship between ciprofloxacin resistance and extended-spectrum beta-lactamase production in Escherichia coli and Klebsiella pneumoniae strains. Clin. Microbiol. Infect. 2004; 10: 72-75.

39. Sturënburg, E. ; \& Mark, D. Extended spectrum $\beta$-Lactamase:implications for the clinical microbiology laboratory, therapy, and infection control. J. Infect.; 2003; 47: 273-95.

40. Raei F, Eftekhar F, Feizabadi MM. Prevalence of Quinolone Resistance Among ExtendedSpectrum beta -Lactamase Producing Uropathogenic Klebsiella pneumoniae. Jundishapur J Microbiol. 2014; 7(6):e22260

41. Horcajada, J.P., Soto, S., Gajewski, A., Smithson, A., Jimenez de Anta, M.T., Mensa, J., Vila, J. and Johnson, J.R. Quinolone resistant uropathogenic Escherichia coli strains from phylogenetic group B2 have fewer virulence factors than their susceptible counterparts. J Clin Microbiol. 2005; 43: 2962-2964.

42. Ewers C., M. Grobbel, I. Stamm, P.A. Kopp, I. Diehl, T. Semmler, A. Fruth, J. Beutlich, B. Guerra, L.H. Wieler and others. 2010. Emergence of human pandemic 025:H4-ST131 CTX-M-15 extended-spectrum-beta-lactamase-producing Escherichia coli among companion animals. J. Antimicrob. Chemother. 65: 651-660.

43. Rahdar M, Rashki A, Miri HR, Rashki Ghalehnoo M. Detection of pap, sfa, afa, foc, and fimadhesinencoding operons in uropathogenic Escherichia coliisolates collected from patients with urinary tract infection. Jundishapur J Microbiol. 2015; 8: e22647.

44. Firoozeh, F., Saffari,M., Neamati, F., and Zibaei, M. Detection of virulence genes in Escherichia coli isolated from patients with cystitis and pyelonephritis. Int. J. Infect. Dis. 2014; 29: 219-222.

45. Servin, A.L. Pathogenesis of Afa/Dr Diffusely Adhering Escherichia coli. Clin Microbiol Rev. 2005 Apr; 18(2): 264-292.

46. Keller R, Ordo nez JG, de Oliveira RR, Trabulsi LR, Baldwin TJ \& Knutton S. Afa, a diffuse adherence fibrillar adhesion associated with enteropathogenic Escherichia coli. Infect Immun. 2002; 70: 2681-2689. 